\title{
Merit Based Re-Distribution of Students in Anatomy Dissection Classes: Method Re-Visited
}

\author{
Nayak S.B $B^{1}$ George ${ }^{1}$, B.M., Mishra, $S^{2}$.
}

\begin{abstract}
We at Melaka Manipal Medical College (Manipal Campus) have adopted merit based re-arrangement of dissection groups of first year medical students during the second term of their anatomy course. This rearrangement had shown improvement in their anatomy scores in the subsequent examinations of the second term. The above distribution caused uneasiness, especially to the students who scored least marks in the first term. Some among them complained of being depressed after the re-distribution. The purpose of our intervention was to reduce the stress and anxiety, but achieve the same or better improvement in the exam scores. The students were redistributed depending on the aggregate of marks of the two exams in the first term. However the groups were not assigned their meritorious ranks. Hence, the students were not told to which meritorious group they belonged to whereas the teachers were aware of the same. This helped the teachers to teach accordingly to the groups. To find out their improvement in the exams, a comparison of their marks in the exams conducted just before and after the intervention was made. The students who scored less were not depressed as their scores were unrevealed to them and to their peers. $66 \%$ students felt this method of redistribution is good and others felt it was satisfactory. Student redistribution with unrevealed ranking almost erased the uneasiness that was there earlier. Most of them were happy and felt that the course was delivered to them at their intellectual level.
\end{abstract}

Key Words: Stress-free, Exam scores, Motivation

\section{Introduction}

In Melaka Manipal Medical College (Manipal campus), the students learn anatomy, physiology and biochemistry in their first year of the course. Their anatomy curriculum includes lectures, practical classes and PBLs. A class of 125 to 200 students is divided into $16-20$ students per group for dissection and demonstration of cadavers.

${ }^{1}$ Department of Anatomy,

Melaka Manipal Medical College (Manipal Campus),

Manipal University,

${ }^{2}$ Madhav Nagar, Manipal. Udupi District. Karnataka State, INDIA. 576104.

\section{Corresponding Author}

Snigdha Mishra

Lecturer in Anatomy

Department of Anatomy

Melaka Manipal Medical College (Manipal Campus)

International Centre for Health Sciences

Manipal University

Madhav Nagar, Manipal

Udupi District

Karnataka State, INDIA.

Email:snigdha.mishra08@gmail.com
For the initial few years of this program, the grouping method was purely based on roll numbers. A few students in each small group (dissection table) dominated all interactions and activities in the groups (Nayak et al., 2005), whereas a few shy or less motivated students always sat behind the dominating ones; and their interactions with their peers and tutors were poor. To overcome these issues, we arranged the groups according to the students' academic performances.

Based on their scores in the exams of the first term, the students were ranked in descending order and redistributed. This was done in such a way, that in each batch the table with the highest number (eg.:- table 6) comprised the academically strongest students and table 1 the academically weakest students. Hence, tables 1 and 2 comprised mainly of students who were academically weak, shy or less motivated. After the redistribution we found that these students performed better in terms of their interactions with teachers and peers. We found that as the groups now contained students of almost similar understanding of the subject, tutoring was more effective. With this new system the 
students instantly knew their strengths and weaknesses and hence started communicating areas of uncertainty to their teachers and group members. This improved their scores in the subsequent examinations. The students' feedback before the university examination revealed that though the students felt this system improved their performance, they felt let down for being labeled as academically poor students.

At the same time the faculty noticed that the academically weak students appeared gloomy and lost at the beginning of the second term. As we wanted to achieve better academic scores with the merit based distribution and eliminate the elements of depression and uneasiness among them, we introduced a new method of redistribution from MBBS batch 30 (2011 March admission).

\section{Objective}

The objective of the study was to distribute the medical students based on their merits in the first semester, to achieve the following:

1. Create a friendly environment at the dissection table with all the students having almost equal scores and levels of understanding. This helps students to have discussions among themselves and not feel left out.

2. Random distribution, makes sure that the students are not labeled as "weak" or "smart", as no one is aware of their "actual table positions" and hence reduces stress.

\section{Method}

The students of the March 2011 admission (Batch 30) $(n=128)$ were redistributed into 6 groups according to their examination scores from the first semester. The academically weakest students were not given the first dissection table as in previous batches. The tables were allotted randomly to the groups irrespective of their academic achievement (The lowest scorers were allotted to table 2, the next group [second lowest scoring group] to table 5 , third group to table 6 , fourth group to table 1, fifth group to table 3 and the top scoring group to table 4). The students were not told about the redistribution criteria. They were completely unaware of their actual meritorious table ranks. Therefore, while students with the same level of understanding and academic scores were grouped together without being aware of their actual ranks, the teachers were aware of the same.

A structured questionnaire containing 8 closed ended and 4 open ended questions was prepared and validated. The questionnaire was introduced to the already redistributed students of batch 30 at the middle of the second term soon after the first summative assessment. The results were tabulated as percentage opinions. To find out their improvement in the exams, a comparison of their marks in the exams conducted just before and after the intervention was made.

\section{Results}

A total of 118 students completed the questionnaire. Overall 64 (54\%) students were not aware about their approximate rank in the class. $71(60 \%)$ were not aware of the criterion used to reshuffle the batch to different tables. Some of the academically lowest scoring students from table 2 and 5 (32\%) were not happy with the current distribution but they did not get depressed after the redistribution as the other students did not discriminate them as the lowest scorers. However, some of the students of the academically best group (20\%) felt stressed because of the competition for achieving excellence. Most of the students $(64 \%)$ felt that they are learning better after the redistribution.

All six teachers who taught the batch felt that there were no visible signs of student dissatisfaction or stress after the redistribution as indicated by body language of the students and their participation in discussions. Also the comparison of their individual marks in the pre and post intervention tests (done after 9 weeks of intervention), showed an improvement in their theory and practical marks. The improvement in the practical exam scores was more significant.

Table 1 shows the questionnaire provided to the students. Figure 1 given below indicates the statistics of opinion of each of the groups. Table 2 indicates the details present in the graph. Pre and post intervention assessment marks for theory and practical assessments are compared in table 3 and 4 respectively. 
Table no 1: Questionnaire given to the students

\section{Q. Nos.}

\section{Questions}

\section{1.}

2.

3.

4.

5.

6.

7.

8.
Are you aware that there was merit based distribution for previous batches after block 2?

Are you aware that the academically weakest students were given table 1 and academically best students were given the last table?

Do you know in which table you would be if we redistributed the class based on the performance in first two blocks? If yes which table.

Do you know what is the criterion used for your batch to redistribute the students after block 2 ?

Are you satisfied with the current method of redistribution?

Were you learning better during block 1 and 2 than in block 3 ?

Are you depressed after the redistribution?

Do you see any difference in teaching on the table after the redistribution?

Figure 1: Affirmative responses for the Questions

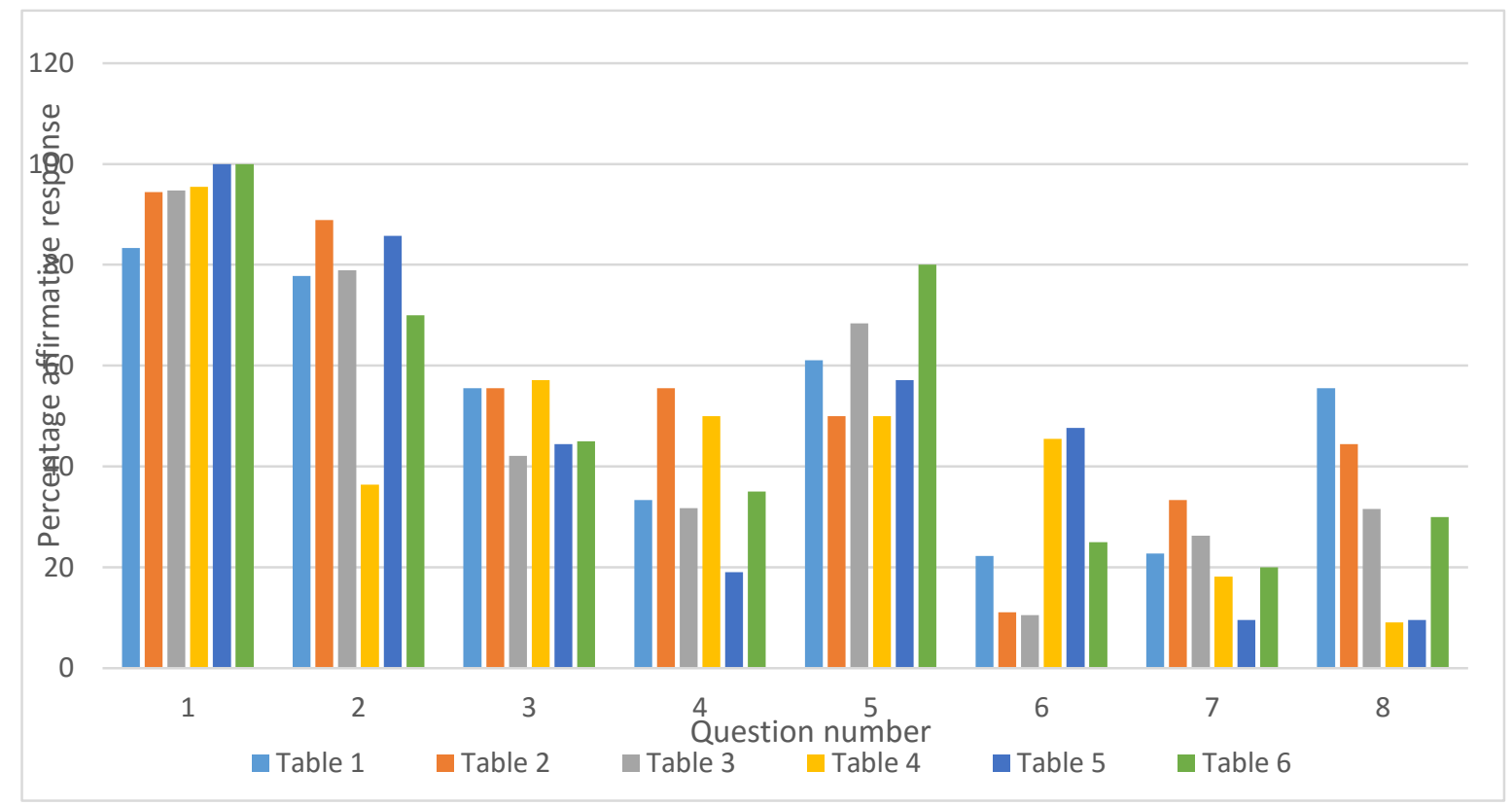


Table no 2: The mean score of various groups of students and their response to question no 3

\begin{tabular}{cccc}
\hline Table number & Number of students & Mean score & $\begin{array}{c}\text { \% correct response } \\
\text { for identifying table }\end{array}$ \\
\hline 1 & 18 & 41 & 60 \\
2 & 18 & 53 & 60 \\
3 & 19 & 62 & 50 \\
4 & 22 & 69 & 31.81 \\
5 & 21 & 76 & 42.85 \\
6 & 20 & 86 & 33.33 \\
\hline
\end{tabular}

Table 3: comparison of pre and post intervention theory assessment marks

Pre- intervention Theory assessment $(n=128) \quad$ Post- intervention Theory assessment $(n=128)$

(max marks=100)

$($ max marks= 100)

Mean: 61.17

Mean: 63.57

SD: 17.01

SD: 13.76

SEM: 1.5

SEM: 1.22

Paired $T$ - test $P$ value (Two tailed $)=0.01$

Table 4: Comparison of pre and post intervention practical assessment marks

\begin{tabular}{cc}
\hline $\begin{array}{c}\text { Pre-intervention practical assessment } \\
(\mathbf{n}=\mathbf{1 2 8}) \text { (max marks=50) }\end{array}$ & $\begin{array}{c}\text { Post- intervention practical assessment } \\
(\mathbf{n}=\mathbf{1 2 8}) \text { (max. marks }=\mathbf{5 0})\end{array}$ \\
\hline Mean: 34.11 & Mean: 39.40 \\
SD: 7.01 & SD: 6.05 \\
SEM: 0.62 & SEM: 0.53 \\
\hline
\end{tabular}

Paired T-Test $P$ value (Two tailed $)=0.001$ 


\section{Discussion}

Our first aim was to determine if the re- allocation with the new method provided a stress free environment to help students become more interactive and motivated learners. With this method we achieved the satisfaction of the students being more active, happy and ready to learn. The questionnaire results also gave us the same picture.

Majority of the students were aware that there was a merit based distribution in dissection classes for previous batches of MBBS. More than $50 \%$ of students were not aware about the current criterion for redistribution, but were satisfied $(>60 \%)$ with the current method.

Though the majority said there was no difference in teaching in the second term and the learning remains the same, very few students said they were depressed with the current method of redistribution. This uneasiness was probably because of having new students in the group and the need for time to get used to the new group. The open ended questions revealed that many liked the current method because there is no discrimination of the weaker students even though there is a rough idea about their performance. Many felt the redistribution made them more hard working. The weaker students felt that they did not have problems with low selfesteem like academically weak students of the senior batches. A few felt that the teachers taught them at par with the academically better students. According to only two students, the better table number allotted to the weaker students created a false illusion of smartness in them which hindered learning, However, this is a statistically insignificant number.

Traditionally in medical schools, dissection hall activities are considered to be the place where medical professionalism is promoted, by faculty and working with peers. This is achieved through activities like team work, discussions and more involvement in small group teaching/ learning (Davidova et al., 2010). However, all students in a group are not of the same intellectual level; the better ones dominate discussions and interactions leaving little or no chance for the weaker ones to open up and interact. With the older method of redistribution, the weaker students found the much needed chance to interact but suffered low self-esteem due to being labeled as the "weaker table" (Nayak et al., 2005). Effectiveness of learning through peer demonstration in laboratories is well studied (Nayak et al., 2005). Results of the above study clearly show the importance of peer learning in the dissection hall (Wilson, et al., 2011; Brueckner \& MacPherson, 2004). Also There are studies suggesting that if a student is not prepared mentally and emotionally before the commencement of the dissection class, anatomy learning won't be complete (Mulu \& Tegabu, 2012). Hence we felt that with the current method we could attain a stress free environment in the dissection hall which made them more comfortable in learning anatomy through dissections. This stress free environment also showed improvements on their exam scores. There was a significant improvement in their marks when the scores in the exams conducted just before and after the intervention were compared.

\section{Conclusion}

The anatomy dissection hall must create a platform for gaining medical professionalism for budding medical professionals. In addition, cadaver dissection is considered to be the best learning tool for anatomy learning. To learn anatomy in a stress free environment and to learn medical professionalism, students must be prepared mentally and emotionally. A merit based but unrevealed table distribution helps the students to learn better in a peaceful environment and helps the teachers to teach more appropriately.

\section{Acknowledgement}

We acknowledge the help of our clerical staff in obtaining the data for this paper.

\section{Conflict of interests}

The authors do not declare any conflict of interests.

\section{References}

Davidova, R. I., Mushatova, P.K. \& Yochkova, S.D. (2010) Professionalism dissected: the role of anatomy faculty in promoting professionalism, Journal of Biomedical and Clinical Research, 3, 1, pp.12-18. 
Brueckner, J.K. \& MacPherson, B.R. (2004) Benefits from peer teaching in the dental gross anatomy laboratory, European Journal of Dental Education, 8, pp. 72-77.

Mulu, A. \& Tegabu, D. (2012) Medical students' attitudinal changes towards cadaver dissection: a longitudinal study, Ethiopian Journal of Health Sciences, 22,1, pp.51-58.

Nayak, S., Ramnarayan, K., Somayaji, S. N. \& Bhat, S. (2005) Merit-based rearrangement of students for better interactions, Advance in Physiology Education, 29, p.183

Wilson, A.B., Williams, P.M., James, M. \& Thorp, L.E. (2011) An Investigation of Alternating Group Dissections in Medical Gross Anatomy, Teaching and Learning in Medicine, 23, 1, pp.46 - 52. 